\title{
Keeping the NHS on course: politicans' proposals for the next 4 years
}

Climatic metaphors describing the state of our economy as chilly, arctic, and frozen are becoming overworked, but it's almost impossible not to think of seagoing terminology to describe what needs to be done to the NHS steadying the ship, battening down the hatches, rearranging the deckchairs and a number of these cropped up in my recent interviews with the three political parties' health spokesmen and a reading of their policy documents.

\section{$* * * *$}

\section{NORMAN LAMB MP}

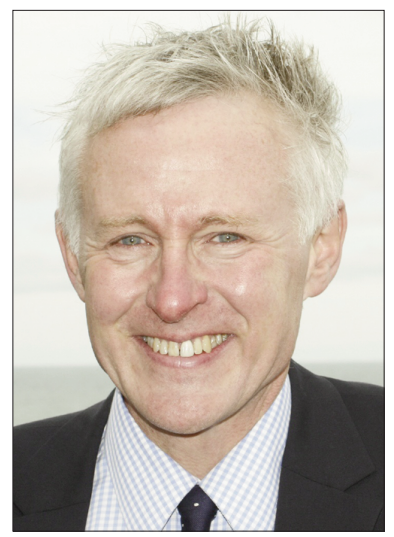

Norman Lamb, the Liberal Democrat Shadow Health Secretary, describes, in the introduction to the LibDem document on the NHS 'A Liberal Blueprint', the current funding problems of the NHS as 'the conditions for a perfect storm', with potentially disastrous consequences. His party's approach to ensuring the survival of the NHS includes an emphasis on decentralisation, on reform of NHS funding, on the development and enfranchisement of the workforce and on supporting patients in taking responsibility for their own health.

According to Lamb, centralised management of the NHS has 'been tested to destruction', and local accountability is the answer. PCTs will give way to local health boards able to raise revenues and determine patterns of expenditure. Strategic health authorities will be abolished, along with large numbers of quangos, inspectorates, and one-third of posts in the Department of Health. The amount spent by the Department of Health on advertising and public relations will be slashed. Payment by Results will be significantly altered, with changes in the tariff and a strong emphasis on the development of Integrated Care Organisations, with primary care, secondary care, community services and, in some instances, social care organisations working together with unified budgets and aspirations, captured in a LibDem neologism 'Competitive Localism'. Returning autonomy to NHS staff is seen as a priority, and the Blueprint document is peppered with examples of engaging, valuing, and rewarding staff in various settings, including John Lewis, a number of NHS organisations, and Kaiser Permanente. Patients have responsibilities as well as rights and the Blueprint includes a robust section on individuals' responsibilities for alcohol-related accident and emergency attendances.

The pre-election summary document published by the LibDems also includes some important and more specific promises, including ensuring 'that local GPs provide out-of-hours care', the introduction of a 'patient premium', to encourage GPs to accept patients from areas with poor health and deprivation scores, and to increase patients' choice of GP along with giving them the right to access their GP by e-mail. The document also includes an important pledge to make it illegal for a local health board (previously a PCT) to allow a doctor to work in the UK for the first time without passing language and competence tests, and identifying a single regulator responsible for patient safety. Although the LibDems plan to scrap Connecting for Health, they promise to give patients better control of their own health records to enable them to take a more active role in managing their health. The overall financial envelope in which these, generally very sensible-sounding proposals are made is unclear but the party has clearly drawn comfort from Professor Nick Bosanquet's calculation that the potential scope for efficiency gains in the NHS is up to $10 \%$ of total spend, equating to over $£ 10$ billion. ${ }^{1}$ The documents say little about the specifics of primary care training or the European Working Time Directive (EWTD), although Lamb himself was clearly concerned about the adverse effects of the EWTD on both clinical training and patient care.

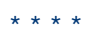

\section{MIKE O'BRIEN MP}

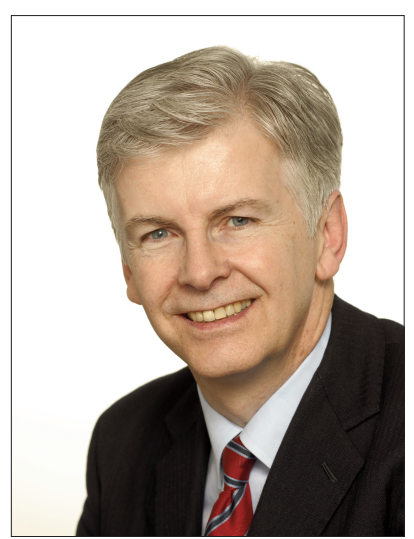

Labour's policy paper 'A Future Fair For $A / l^{\prime 2}$ includes strong statements about early diagnosis achieved by the extension of screening programmes for breast and bowel cancer and aortic aneurysm, and the use of health checks to identify and intervene in vascular risk factors. There are further guarantees on access to investigations for patients suspected of having cancer. Labour appear to be committed to the polyclinic vision - 152 GP-led health centres, one in each PCT, on top of existing services - and to improving access to primary care with more one-stop and walk-in centres. Their 
public health agenda focuses particularly on promoting healthy lifestyle choices, further restricting the availability of tobacco products, and on improving mental health by providing greater access to psychological treatments.

Mike O'Brien is one of the present Labour Health Ministers and he was very clear that, at least for the next 2 years, funding for the NHS will continue to increase, although at lower levels than we have become used to, and that NHS funding will be 'locked' until 2014. Preemptive cuts are off the agenda, patient safety and standards of care are central, and the £15-20 billion savings required will be, whenever possible, achieved within the NHS budget and reinvested. Protection of the NHS for the Labour party is, O'Brien states, axiomatic.

Labour are putting a lot of faith in their QIPP programme - Quality, Innovation, Productivity and Prevention. This means working more efficiently, saving money, inventing new methods of care which are both more effective and cheaper, reskilling and re-organising the workforce, and focusing on innovation. An important component of this vision is joint working between primary and secondary care, as it is for the LibDems, and there are a number of good examples of innovative, integrated care where costs have been constrained and care improved. However, the primary-secondary care divide is still problematic, PCT management is variable, and there are still not enough clinicians involved in health services management. Labour are committed to improving out-of-hours services by encouraging greater engagement of GPs, fostering better relationships between PCTs and Local Medical Committees and improving GPs' ability to influence service development without going the extra step of providing the 'hard budgets', proposed by the Tories.

O'Brien sees a reinvigoration of the NHS and a rearticulation of its founding values as being at the heart of persuading professionals to rise to the challenges of these changing ways of working. Although he recognises the importance of the quality of local management, he has not given up on central direction and is wary of the extreme devolvement of planning and funding proposed by other parties. $\mathrm{He}$ is keen to strengthen vocational training for general practice, although the timing of this relatively expensive development still needs to be decided, and is also committed to supporting medical education, commenting that we need to become more self-sufficient in the production of doctors working in the UK.

$$
* * * *
$$

\section{MARK SIMMONDS MP}

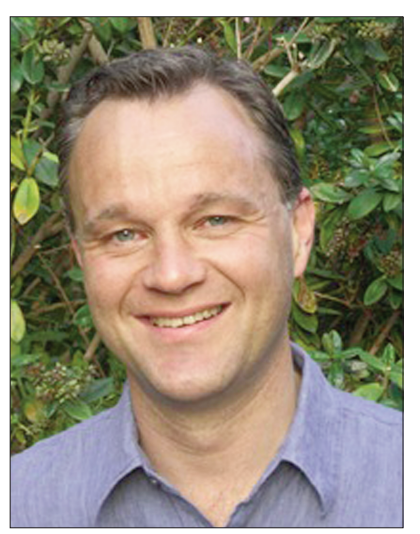

Patient-centredness, patient outcomes, and public health are the main planks of Conservative NHS reform. Mark Simmonds, their Shadow Health Minister, was also clear that the NHS budget was safe and that it would be possible to save substantial amounts of money in some of the same ways as those proposed by the LibDems, particularly by cutting bureaucracy and duplication of functions among quangos to reduce the cost of NHS administration by about one-third. He was also clear that savings need to be reinvested into the health service, and not passed to other budgets, although ringfencing NHS funding is inevitably going to lead to difficulties in negotiation with other Government spending departments.

The Tories are keen to promote 'hard budgets' for GPs, in which consortia of practices serving populations of perhaps 100-150 000 people will be given real money to use to commission services, in which all GPs in the area covered by each consortium will be involved. They will be required to reinvest savings in the services provided by their practices and will be deterred from self-commissioning. GPs' pay will continue to be related to the quality of care they deliver. This is not, Simmonds is at pains to point out, a return to fundholding but a better way of getting GPs involved in designing and delivering locally-relevant services, in which they will be assisted by experts from the NHS and the independent sector. He wants to see the clinical relevance of QOF improved, for GPs to maintain their gatekeeping role, and for joint work between primary and secondary care to be more focused on patient outcomes, patient information, and patient choice rather than on measures of process. Changes in the hospital tariff and the Payment By Results system are almost certain to take place. Like the other parties, the Tories are keen to increase GPs' involvement in out-of-hours care, but without returning to the pre-2004 legal liability for 24-hour care of patients. Stricter checks on doctors coming from outside the UK in terms of their linguistic abilities and their familiarity with formularies and prescribing will be essential.

The Conservative Draft Manifesto ${ }^{3}$ was also strong on public health, and included a proposal to change the name of the Department of Heath to the Department of Public Health, to provide public health funding weighted towards the poorest areas with the worst health outcomes, and single budgets for patients with long-term conditions, 
combining health and social care funding. Radical ideas about introducing a national social care system remain highly controversial.

Simmonds seems committed to strengthening general practice through improving vocational training, to reversing, where contractually possible, central directives to set up inappropriate poly-systems and polyclinics and also to overhaul Connecting for Health, with an emphasis on devolved, local development of effective IT systems. He is keen on more joint working between pharmacists and primary care clinicians, wishes to preserve the NHS R\&D budget and was refreshingly positive about increasing the linkage between academic and service general practice.

\section{WHAT WILL THEY DO?}

All three parties have good ideas to make positive changes to the NHS, but funding will be the key. It seems difficult to believe that the NHS budget can be completely protected, because of the knock-on effects on other government departments. Much of the costcontainment proposed is predicated on efficiency savings and more costeffective working on a scale never before delivered by the NHS. A heavy reliance on QIPP and on transforming working patterns across the primary care interface must be viewed with some scepticism, and it is unclear to me how central direction or local initiatives will kick in quickly enough to keep the books balanced. In the end this will come down to the quality of people working in the $\mathrm{NHS}$ - the quality of clinical leadership, of management, of patient care, and of support services. The commitment of the 1.4 million employees of the NHS to the service has suffered a series of dents in recent years. It is time for the injection of a large dose of altruism. The next administration needs to avoid radical service redesign, provide realistic rather than delusory plans for the short and medium term future, be prepared to examine alternative funding models, reengage and value the workforce, and build upon the considerable strengths of the service while being unafraid of identifying and penalising poor and unsafe practice, whether in the board room or the operating theatre.

\section{Roger Jones}

\section{REFERENCES}

1. The NHS: a liberal blueprint. http://www.centreforum.org/assets/pubs/nhs-aliberal-blueprint.pdf (accessed 7 Apr 2010).

2. Labour. A future fair for all. http://www2.labour.org.uk/home (accessed 7 Apr 2010).

3. Conservatives Draft Manifesto 2010. Chapter One. Our reform plan for the NHS.

http://media.conservatives.s3.amazonaws.com/mani festo/cpmanifesto2010_hires.pdf (accessed 13 Apr 2010)

DOI: 10.3399/bjgp10X501976 